\title{
Metodologias para determinação da digestibilidade de dietas contendo fontes proteicas vegetal ou animal em cães
}

\author{
Methodology for determination of digestibility of diets containing vegetable or animal protein \\ sources in dogs
}

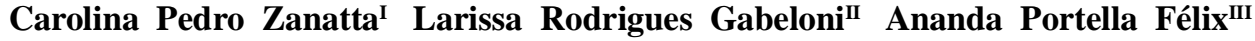 \\ Cleusa Bernardete Marcon de Brito ${ }^{I}$ Simone Gisele de Oliveira ${ }^{\text {III* }}$ Alex Maiorka ${ }^{\text {III }}$
}

RESUMO

\begin{abstract}
Objetivou-se avaliar diferentes metodologias de determinação da digestibilidade em cães, alimentados com duas dietas contendo fontes proteicas animal (farinha de vísceras de aves - FVA) e vegetal (farelo de soja - FS). As metodologias avaliadas foram: colheita total de fezes $(C T F)$ e os indicadores cinza insolúvel em ácido (CIA), fibra em detergente ácido (FDA) e fibra bruta (FB). Foram utilizados 8 cães adultos, em delineamento Cross over, em parcela subdividida no tempo (parcela: fontes proteicas; $e$ subparcela: metodologias de digestibilidade). $O$ período experimental foi constituído por cinco dias de adaptação, com cinco dias de colheita total de fezes. A dieta contendo FS apresentou maior CDA da PB, enquanto a dieta contendo FVA apresentou maior CDA dos demais nutrientes e energia metabolizável (EM). Os CDA e EM determinados pela CTF e pelos indicadores não diferiram entre si, podendo ser determinados pelos indicadores FB, FDA e CIA, independentemente da fonte proteica da dieta.
\end{abstract}

Palavras-chave: ensaio de digestibilidade, indicadores, ingredientes proteicos.

\section{ABSTRACT}

The objective was to evaluate different methods of measuring digestibility in dogs fed two diets containing animal (poultry by products - PBP) and vegetable (soybean meal - SBM) protein sources. The methods evaluated were: total fecal collection (TFC) and indicators: acid insoluble ash (AIA), acid detergent fiber $(A D F)$ and crude fiber (CF). Eight dogs were distributed in Cross Over in split plots (plot: sources of protein; subplot: methods for digestibility), fed by five days of adaptation and five days of total fecal collection. The diet containing SBM had a higher ADC of CP, while the diet containing POM showed higher ADC of all nutrients and metabolizable energy (ME). The ADC and $M E$ determined by the TFC and the indicators did not differ. Thus, the ADC of diets in dogs can be determined by TFC and CF, ADF and AIA indicators, regardless of source of dietary protein.

Key words: digestibility assay, indicators, protein ingredients.

\section{INTRODUÇÃO}

Embora os ingredientes proteicos de origem vegetal possuam menor variação em seu valor nutricional, quando comparado aos de origem animal, ainda são escassos estudos disponíveis com relação à digestibilidade destes para animais de companhia (CLAPPER et al., 2001). Por outro lado, a composição nutricional e a biodisponibilidade dos nutrientes das farinhas de origem animal são inconsistentes, pois são influenciadas, entre outros fatores, pelo nível de inclusão dos diferentes tecidos animais e pela temperatura e tempo de processamento da farinha (FAHEY \& HUSSEIN, 1998).

Além da análise bromatológica desses nutrientes, é importante realizar ensaios de digestibilidade para averiguação dos dados nutricionais, os quais podem ser realizados por diferentes metodologias. No entanto, a falta de padronização e definição de metodologias precisas, exatas e exequíveis para aferição da digestibilidade e energia metabolizável de ingredientes em cães

'Programa de Pós-graduação em Medicina Veterinária, Universidade Federal do Paraná (UFPR), Curitiba, PR, Brasil.

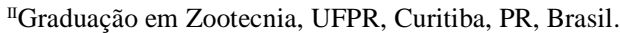

IIIDepartamento de Zootecnia, UFPR, Rua dos Funcionários, 1540, Bairro Cabral, 80035-050, Curitiba, PR, Brasil. E-mail: sgoliveira@ufpr.br. *Autor para correspondência. 
contribui para a escassez de dados sobre o assunto (FÉLIX et al., 2010). Existem, basicamente, dois métodos para a realização desses ensaios: o método convencional ou de coleta total e o método dos indicadores ou substâncias índices. Conforme citado por SALES \& JANSSENS (2003), o primeiro requer controle da quantidade do alimento ingerido e das fezes excretadas, exigindo também maior tempo de coleta. Já o segundo pode ser realizado em menor espaço de tempo e não há necessidade da mensuração do que é ingerido e excretado.

Como forma de indicadores, têm sido utilizados constituintes naturais da dieta que apresentam baixa digestibilidade (BERCHIELLI et al., 2000). No entanto, a composição da dieta, como níveis de minerais e fibras, pode influenciar na estimativa da digestibilidade desse método, devido às alterações na taxa de passagem da digesta e interações do indicador com componentes da dieta (DOURADO et al., 2010). Dessa forma, objetivouse avaliar a digestibilidade de dietas contendo fontes proteicas animal ou vegetal, pela colheita total de fezes e diferentes indicadores.

\section{MATERIAL E MÉTODOS}

Foram utilizados oito cães adultos $(2,1$ a 2,3 anos) da raça Beagle (quatro machos e quatro fêmeas), com peso médio de $8,6+1,4 \mathrm{~kg}$. Os animais passaram por exame clínico prévio e foram vacinados e desverminados. Durante o ensaio de digestibilidade, os animais foram alojados em gaiolas metabólicas de aço inoxidável, medindo $0,7 \mathrm{~m}$ de comprimento $\mathrm{x}$ $0,6 \mathrm{~m}$ de altura $\mathrm{x} 0,5 \mathrm{~m}$ de largura.

Foram avaliados quatro métodos para determinação da digestibilidade: colheita total de fezes (CTF) e os indicadores: cinza insolúvel em ácido (CIA), fibra em detergente ácido (FDA) e fibra bruta (FB), de duas dietas isonutritivas, contendo $37,5 \%$ de farinha de vísceras de aves (FVA) ou 30\% de farelo de soja (FS) como principal fonte proteica. A composição química das fontes proteicas utilizadas e as variáveis qualitativas do processamento do FS estão apresentadas na tabela 1 .

As dietas foram moídas a $0,8 \mathrm{~mm}$ e extrusadas em extrusora de rosca simples (Ferraz, E-130, Ribeirão Preto, Brasil). A qualidade do processo foi aferida por meio das mensurações da densidade dos extrusados na saída da extrusora, a qual foi considerada adequada entre $428-462 \mathrm{~g} \mathrm{~L}^{-1}$. As fórmulas e a composição química analisada das dietas experimentais estão apresentadas na tabela 2 .

$\mathrm{O}$ ensaio de digestibilidade seguiu as recomendações da AAFCO (2004), com cinco dias de adaptação às dietas e instalações e cinco dias de colheita total de fezes por período. Os animais foram alimentados duas vezes ao dia (7 e 15h) em quantidade suficiente para suprir suas necessidades de energia metabolizável (NEM), segundo preconizado pelo NRC (2006): NEM $\left(\mathrm{kcal} \mathrm{dia}^{-1}\right)=130 \mathrm{x}$ peso corporal $^{0,75}$. A água foi fornecida ad libitum. Todas as fezes foram colhidas, no mínimo duas vezes ao dia, pesadas e congeladas $\left(-14^{\circ} \mathrm{C}\right)$ em recipientes individuais, constituindo um composto de fezes de cada animal por período de coleta.

As fezes dos cães foram avaliadas a partir dos valores de matéria seca total nas fezes, produção de fezes, escore e $\mathrm{pH}$ fecal $(2,0 \mathrm{~g}$ de fezes frescas, diluídas em $20 \mathrm{~mL}$ de água destilada, medido com pHmetro digital). Foi avaliado o escore das fezes, sempre pelo mesmo pesquisador, por meio de pontuação variando de 1 a 5, sendo 1: fezes líquidas e

Tabela 1 - Composição química (expressa na matéria natural) das fontes proteicas e variáveis qualitativas do farelo de soja.

\begin{tabular}{lcc}
\hline Composição química & Farelo de soja & Farinha de vísceras de aves \\
\hline Matéria seca $(\%)$ & 89,88 & 93,45 \\
Proteína bruta $(\%)$ & 46,30 & 61,23 \\
Fibra bruta $(\%)$ & 6,58 & - \\
Extrato etéreo em hidrólise ácida (\%) & 4,05 & 14,54 \\
Matéria mineral $(\%)$ & 6,40 & 16,98 \\
Cinza insolúvel em ácido $(\%)$ & 0,63 & 0,43 \\
Extrativos não-nitrogenados $(\%)$ & 26,56 & 7,25 \\
Energia Bruta $\left(\mathrm{kcal} \mathrm{kg}^{-1}\right)$ & 4.256 & 4.868 \\
----------------------------------------- \\
Urease $(\Lambda$ pH)
\end{tabular}


Tabela 2 - Ingredientes e composição química analisada das dietas experimentais.

\begin{tabular}{|c|c|c|}
\hline Ingredientes $(\%)$ & Farinha de vísceras de aves & Farelo de soja \\
\hline Milho & 50,21 & 44,01 \\
\hline Farelo de soja & - & 30,00 \\
\hline Farinha de vísceras de aves & 37,5 & 13,70 \\
\hline Óleo de frango & 6,00 & 6,00 \\
\hline Hidrolisado de fígado de aves líquido & 3,00 & 3,00 \\
\hline Hidrolisado de fígado de aves pó & 1,00 & 1,00 \\
\hline Celite $^{\mathrm{TM}}$ & 1,00 & 1,00 \\
\hline Suplemento mineral-vitamínico* & 0,50 & 0,50 \\
\hline Cloreto de sódio & 0,50 & 0,50 \\
\hline Antioxidante (propionato de amônio) & 0,05 & 0,05 \\
\hline Antifúngico (BHT e BHA) & 0,24 & 0,24 \\
\hline Matéria seca & 92,50 & 92,75 \\
\hline Matéria mineral & 8,91 & 7,02 \\
\hline Cinza insolúvel em ácido & 1,44 & 1,16 \\
\hline Proteína Bruta & 28,11 & 28,63 \\
\hline Extrato etéreo em hidrólise ácida & 15,62 & 13,50 \\
\hline Fibra bruta & 3,59 & 4,46 \\
\hline Extrativos não-nitrogenados ${ }^{\mathrm{a}}$ & 43,77 & 46,39 \\
\hline Energia Metabolizável $\left(\mathrm{kcal}^{\left.100 \mathrm{~g}^{-1}\right)^{\mathrm{b}}}\right.$ & 411,40 & 394,94 \\
\hline
\end{tabular}

*Suplemento mineral-vitamínico (conteúdo $\mathrm{kg}^{-1}$ ): Vit. A: 16.900UI, Vit. D3: 2.340UI, Vit. E: 104ppm, Vit. K: 1,3ppm, Vit. B1:3,9ppm, Vit. B2: 6,5pm, Ácido pantotênico: 19,5ppm, Niacina: 32,5ppm, Colina: 1.150,75ppm, Zinco: $156 \mathrm{ppm}$, Ferro: 104ppm, Cobre: 13ppm, Iodo: 2,6ppm, Manganês: $45,5 \mathrm{ppm}$, Selênio: 0,26pm.

${ }^{\mathrm{a}} \mathrm{ENN}-100$ - (proteína bruta $\%$ + matéria mineral $\%$ + fibra bruta $\%$ + extrato etéreo em hidrólise ácida)

${ }^{\mathrm{b}}$ Estimado segundo o NRC (2006).

5: fezes duras e ressecadas, produzidas em pequenos pedaços quebradiços.

Após o período de coleta, as fezes foram descongeladas, homogeneizadas e secas em estufa de ventilação forçada à $55^{\circ} \mathrm{C}$ (MS55). Após secas, as fezes e os alimentos foram moídos a $1 \mathrm{~mm}$ e analisados quanto à matéria seca à $105^{\circ} \mathrm{C}$ (MS105), proteína bruta $(\mathrm{PB})$, fibra bruta $(\mathrm{FB})$, extrato etéreo em hidrólise ácida (EEA) e matéria mineral (MM), segundo à AOAC (1995). A energia bruta (EB) foi determinada em bomba calorimétrica. As cinzas insolúveis em ácido (CIA) foram determinadas de acordo com metodologia descrita por VAN KEULEN \& YOUNG (1977). Os extrativos não-nitrogenados (ENN, \%) foram estimados por: 100-(umidade\% +PB\%+EEA\%+FB\%+MM\%), a matéria orgânica (MO, \%) por: $100-\mathrm{MM} \%$ e a matéria seca original das fezes obtida por: (MS55xMS105)/100. Para o controle do processamento térmico do farelo de soja, foram determinados a atividade ureásica e o índice de proteína dispersível, segundo a AOCS (1980a,b).

Os coeficientes de digestibilidade aparente (CDA) foram calculados com base nos resultados laboratoriais das dietas e fezes, segundo o método da coleta total de fezes (CTF) e indicadores (I):

$\mathrm{CDA}_{\mathrm{CTF}}(\%)=\frac{(\mathrm{g} \text { nutriente ingerido }-\mathrm{g} \text { nutriente excretado }) \times 100}{(\mathrm{~g} \text { nutriente ingerido })}$
$\mathrm{CDA}_{\mathrm{I}}(\%)=100-\left[\frac{(\% \text { indicador no alimento) } \mathrm{x} \text { (\%nutriente nas fezes) }}{\text { (\%indicador nas fezes) (\%nutriente no alimento) }} \times 100\right]$

A taxa de recuperação dos indicadores foi determinada pela relação entre a quantidade de indicador ingerida e a quantidade de indicador excretado nas fezes. A taxa de fluxo da digesta foi determinada dividindo-se a ingestão dos indicadores (g/dia) pela concentração dos indicadores nas fezes. A CIA foi corrigida para sua taxa de recuperação (CIAc) por meio da razão: (\% CIA nas fezes/\% taxa de recuperação) x 100.

A Energia Metabolizável (EM) foi estimada segundo a AAFCO (2004) para a CTF e I, sendo:

$\mathrm{EM}_{\mathrm{CTF}}\left(\mathrm{kcal} \mathrm{kg}^{-1}\right)=\left\{\mathrm{kcal} \mathrm{g}^{-1} \mathrm{~EB}\right.$ ingeridakcal $\mathrm{g}^{-1}$ EB excretada nas fezes-[(g PB ingerida-g PB excretada nas fezes) $\left.\left.\mathrm{x} 1,25 \mathrm{kcal} \mathrm{g}^{-1}\right]\right\} / \mathrm{g}$ alimento ingerido 
$\mathrm{EM}_{\mathrm{I}}\left(\mathrm{kcal} \mathrm{kg}^{-1}\right)=\left\{\mathrm{kcal}^{-1} \mathrm{~EB}\right.$ alimento[kcal g-1 EB fezes x (\% I alimento/\% I fezes)] $\}-\{\%$ PB alimento-[\% PB fezes x (\% I alimento/\% I fezes)] $\mathrm{x} 1,25\}$

Os resultados foram analisados de acordo com delineamento Cross over, em parcela subdividida no tempo (parcela: fontes proteicas; e subparcela: metodologias de digestibilidade). Os dados foram previamente analisados quanto à sua normalidade (Shapiro-Willk) e, quando atendida essa premissa, foram analisados utilizando o procedimento GLM do pacote estatístico SAS (1996). Os dados foram submetidos à análise de variância e as médias obtidas foram comparadas pelo teste Tukey a $5 \%$ de probabilidade. $\mathrm{O}$ escore fecal foi analisado pelo teste Kruskal-Wallis, considerando $5 \%$ de probabilidade como diferença significativa.

\section{RESULTADOS E DISCUSSÃO}

A dieta contendo FVA apresentou maiores CDA dos nutrientes avaliados quando comparada à dieta contendo FS, com exceção da digestibilidade da $\mathrm{PB}$, que foi superior na de origem vegetal (Tabela 3). Os resultados são corroborados por ZUO et al. (1996), CARCIOFI et al. (2006) e CLAPPER et al. (2001), que observaram maior digestibilidade de PB para dietas contendo soja em relação às dietas contendo farinha de aves. Esse resultado se deve possivelmente às variações na composição e no processamento dos ingredientes de origem animal, sendo que a FVA pode apresentar diferentes proporções de cabeça, pescoço, pés, dorso, intestinos e até a inclusão indevida de penas (CARCIOFI et al., 2006).

Quanto aos métodos de avaliação da digestibilidade, não foram encontradas diferenças entre si, além de não haver interação entre estes e as fontes proteicas utilizadas na dieta $(\mathrm{P}>0,05)$. $\mathrm{O}$ uso dos indicadores FB e CIA se mostraram adequados na predição da digestibilidade das frações nutricionais da dieta contendo $\mathrm{FS}$, com taxas de recuperação próximas a $100 \%(98,1 \%+2,81$ para a CIA e $99,2 \%+3,98$ para a $\mathrm{FB}$ ).

Entretanto, a CIA superestimou os CDA da dieta contendo FVA (taxa de recuperação de $105,2 \%+1,89$ contra $101,5 \%+4,23$ para a FB), como também encontrado em outros estudos, relatando que a CIA superestimou a digestibilidade das dietas (STEIN et al., 2006, LEÃO et al., 2008). Esse fato pode ter ocorrido pela incompleta solubilização de minerais solúveis em $\mathrm{HCl}$, como o cálcio e o fósforo nas fezes, superestimando o teor de CIA nas fezes dos cães alimentados com a dieta contendo FVA como principal fonte proteica.

Apesar disso, SALES \& JANSSENS (2003) citam que o método de VAN KEULEN \& YOUNG (1977), com duas queimas da amostra na mufla, com tratamento de $\mathrm{HCl}$ entre as queimas, como o realizado no presente estudo, é o mais adequado para se evitar superestimativa da digestibilidade da dieta.

Tabela 3 - Coeficientes de digestibilidade aparente (CDA) e energia metabolizável (EM keal kg${ }^{-1}$ ), avaliados pelos métodos da coleta total de fezes (CTF) e indicadores: cinza insolúvel em ácido (CIA), fibra bruta (FB) e fibra em detergente ácido (FDA), de dietas contendo farinha de vísceras de aves (FVA) ou farelo de soja (FS) como principal fonte proteica em cães.

\begin{tabular}{lllllllll}
\hline Fatores & & MS & MO & PB & EFA & ENN & EB & EM \\
\hline \multirow{2}{*}{ Proteico (P) } & FVA & 81,2 & 86,9 & 82,7 & 94,8 & 91,5 & 87,9 & 4464,8 \\
& FS & 80,7 & 84,0 & 84,0 & 90,7 & 89,0 & 84,9 & 4198,7 \\
& & & & & & & & \\
& CIA & 82,3 & 86,4 & 84,6 & 93,2 & 91,0 & 87,3 & 4379,7 \\
Método (M) & FB & 80,9 & 85,4 & 83,2 & 92,8 & 90,0 & 86,4 & 4335,0 \\
& FDA & 80,8 & 85,5 & 83,4 & 92,8 & 90,3 & 86,5 & 4330,0 \\
& CTF & 79,7 & 84,6 & 82,8 & 92,3 & 89,8 & 86,1 & 4312,2 \\
EPM & & & & & & & & \\
& & 0,43 & 0,39 & 0,46 & 0,45 & 0,36 & 0,46 & 21,16 \\
& & & & & & & & \\
Probabilidades & P & 0,422 & $<0,001$ & 0,029 & $<0,001$ & $<0,001$ & $<, 001$ & $<0,001$ \\
& PxM & 0,059 & 0,063 & 0,073 & 0,358 & 0,613 & 0,059 & 0,085 \\
& 0,784 & 0,853 & 0,772 & 0,971 & 0,966 & 0,850 & 0,843 \\
\hline
\end{tabular}

MS: matéria seca; MO: matéria orgânica; PB: proteína bruta; EEA: extrato etéreo em hidrólise ácida; ENN: extrativos não-nitrogenados; EB: energia bruta; EPM: erro padrão da média. 
Desse modo, deve-se verificar a metodologia mais adequada para determinação da CIA, particularmente em amostras com alto teor de resíduo mineral, para se evitar que minerais solúveis em $\mathrm{HCl}$ sejam erroneamente contabilizados como CIA.

Visando a minimizar o erro na determinação da digestibilidade e EM da dieta com FVA, os valores de CIA foram corrigidos para $100 \%$ de recuperação. Embora essa prática não seja usual, uma vez que depende da contabilização exata da quantidade de alimento consumida e das fezes excretadas, tirando o propósito do método dos indicadores, pode ser utilizada quando conveniente para corrigir os valores de digestibilidade obtidos, como relatado por DOURADO et al. (2010).

A FB foi efetiva na determinação dos CDA de todas as dietas, embora sua taxa de recuperação tenha apresentado maior coeficiente de variação que a da CIA, com valores mínimos de recuperação de $73,4 \%$ vs. $84,9 \%$ e máximos de $112,4 \%$ vs. $109,4 \%$ para a FB e CIA, respectivamente. Além disso, a FB resultou em maior erro padrão da média (EPM), obtido para os CDAs e EM, em relação aos dados obtidos com a CIA e a CTF, os quais apresentaram EPM semelhante.

A fração FB corresponde ao resíduo insolúvel após fervura da amostra com ácido e álcali, o qual é composto basicamente por celulose, lignina e parte da hemicelulose insolúvel (AOAC, 1995). Os cães não produzem enzimas para digerir os carboidratos estruturais, sendo que a fração fibrosa insolúvel sofre mínima alteração no trato gastrintestinal (NRC, 2006), com digestibilidade aparente da celulose variando de $-0,2$ a $1,9 \%$ nessa espécie (LEWIS et al., 1994). A taxa de recuperação da $\mathrm{FB}$ próxima a $100 \%$ obtida confirma a incapacidade dos cães em digerir essa fração.

Avaliando métodos para predizer a digestibilidade dos alimentos em gatos, CARCIOFI et al. (1998) demonstraram que a FB pode ser utilizada, não diferindo dos resultados obtidos com a CTF e a FDA. Os autores ainda relatam que variações nos CDA, obtidas por meio da FB, podem estar relacionadas com os erros analíticos inerentes à sua determinação laboratorial. Desse modo, afere-se que a CIA pode ser um método de predição da digestibilidade mais preciso e exato que a FB, em dietas contendo baixo teor de minerais solúveis em $\mathrm{HCl}$.

A FDA apresentou valores muito próximos aos da FB, mostrando-se também eficiente na determinação de CDA. JáLÔBO JÚNIOR et al. (2001) relataram que a FDA subestimou a digestibilidade aparente em cães de todos os nutrientes, apresentando menor taxa de recuperação, quando comparada aos métodos de CIA e CTF. Do mesmo modo, BERCHIELLI et al. (2000) encontraram que o indicador FDA apresentou resultados semelhantes aos da CTF, quando incubados durante seis dias (144 horas), enquanto que e a CIA subestimou a digestibilidade, devido à baixa recuperação.

No presente estudo, observou-se que os cães que consumiram dietas a base de FS apresentaram maior massa de fezes e mais úmidas (Tabela 4). Tal fato se deve à composição da soja, que possui carboidratos indigestíveis, prejudicando a digestibilidade e as características das fezes dos cães. Porém, segundo FÉLIX et al. (2010), o processamento térmico da soja, além de eliminar os fatores termolábeis, provoca a ruptura da parede celular, tornado os nutrientes mais disponíveis ao processo de digestão.

Resultados semelhantes para característica das fezes foram observados por CLAPPER et al. (2001), em que a inclusão da soja aumentou a massa fecal, mas que também afirmaram que o processamento pode diminuir a produção de excretas com alto percentual de água. CARCIOFI et al. (2006) relataram que os animais alimentados com dietas de

Tabela 4 - Características das fezes de cães alimentados com dietas contendo farinha de vísceras de aves (FVA) ou farelo de soja (FS), como principal fonte proteica.

\begin{tabular}{llcccc}
\hline & Matéria seca (\%) & Escore & pH & Fezes* $^{*}$ \\
\hline \multirow{2}{*}{ Proteico (P) } & FVA & 41,9 & $3,9^{\mathrm{a}}$ & $6,89^{\mathrm{a}}$ & $0,16^{\mathrm{b}}$ \\
& FS & 29,1 & $3,0^{\mathrm{b}}$ & $6,41^{\mathrm{b}}$ & $0,21^{\mathrm{a}}$ \\
FPM & & & & \\
P & & 1,39 & 0,11 & 0,068 & 0,007 \\
\hline
\end{tabular}

EPM: erro padrão da média. *Produção de fezes na matéria natural $(\mathrm{g}) /$ matéria seca ingerida $(\mathrm{g}) /$ dia.

${ }^{a, b}$ Médias na mesma coluna com letras distintas diferem pelo teste $\mathrm{F}(\mathrm{P}<0,05)$ ou medianas pelo teste Kruskal-Wallis (escore) $(\mathrm{P}<0,05)$.

Ciência Rural, v.43, n.4, abr 2013. 
origem animal apresentaram fezes com maior teor de matéria seca em relação aos alimentados com dieta a base de FS. Isso se deu, como citado anteriormente, provavelmente, em decorrência do alto CDA da matéria orgânica e do maior teor de cinzas da FVA.

\section{CONCLUSÃO}

O uso de indicadores fibra detergente ácido e fibra bruta se mostraram eficientes na estimativa de digestibilidade de dietas em cães, podendo ser utilizados independente de a fonte proteica ser de origem animal ou vegetal. A utilização do indicador CIA, em função da taxa de recuperação, pode resultar em superestimativa da digestibilidade.

\section{COMITÊ DE ÉTICA E BIOSSEGURANÇA}

O experimento foi aprovado pela Comissão de Ética ao Uso de Animais, protocolo n.012/2008, do Setor de Ciências Agrárias da Universidade Federal do Paraná em 15 de setembro de 2008.

\section{REFERÊNCIAS}

AMERICAN OIL CHEMISTS SOCIETY (AOCS). Urease activity. Champaign, IL., 1980a. 77p. (Official Method Ba 9-58.)

AMERICAN OIL CHEMISTS SOCIETY (AOCS). Protein dispersibility index. Champaign, IL., 1980b. 77p. (Official Method Ba 10-65).

ASSOCIATION OF THE OFFICIAL ANALITICAL CHEMISTS (AOAC). Official and tentative methods of analysis. 16.ed. Arlington, 1995. 2000p

ASSOCIATION OF AMERICAN FEED CONTROL OFFICIALS -AAFCO. Dog and cat nutrient profiles. Official Publication of the Association of American Feed Control Officials Incorporated. Oxford: AAFCO, 2004. 276p

BERCHIELLI, T.T. et al. Avaliação de indicadores internos em ensaios de digestibilidade. Revista Brasileira de Zootecnia, v.29 (3), p.830-833, 2000. Available from : <http://www.scielo.br/pdf/ rbz/v29n3/5830.pdf >. Accessed: 20 set. 2011.

CARCIOFI, A.C. et al. Uso de indicadores internos na avaliação da digestibilidade aparente de alimentos para gatos - comparação de métodos. Ciência Rural, v.28, n.2, p.299-302, 1998. Available from: <http://www.scielo.br/pdf/cr/v28n2/a20v28n2.pdf>. Accessed: 14 set. 2011.

CARCIOFI, A.C. et al. Avaliação de dietas com diferentes fontes proteicas para cães adultos. Revista Brasileira de Zootecnia, v.35, n.3, p.754-760, 2006. Available from: <http://www.scielo.br/ pdf/rbz/v35n3/30066.pdf >. Accessed: 22 set. 2011.

CLAPPER, G.M. et al. Ileal and total tract digestibilities and fecal characteristics of dogs as affected soybean protein inclusion in extruded diets. Journal of Animal Science, v.79, p.15231532, 2001. Available from: <http://www.animal-science.org/ content/79/6/1523.full.pdf >. Accessed: 29 set. 2011.
DOURADO, L.R.B. et al. Poultry feed metabolizable energy determination using total or partial excreta collection methods. ACTA, v.12, n.2, p.129-132, 2010. Available from: <http://www. scielo.br/pdf/rbca/v12n2/v12n2a10.pdf >. Accessed: 20 set. 2011.

FAHEY JR., G.C.; HUSSEIN, H.S. The nutritional value of alternative raw materials. Petfood Industry, Maio/Junho, p.2434, 1998.

FELIX, A.P. Avaliação nutricional de derivados proteicos de soja para cães. 2011. 188f. Tese (Doutorado em Ciências Veterinárias) - Setor de Ciências Agrárias, Universidade Federal do Paraná, Curitiba, PR. Available from: <http://dspace.c3sl.ufpr. br/dspace/bitstream/handle/1884/25585/tese_Ananda_Portella_ Felix.pdf?sequence=1>. Accessed: 15 set. 2011 .

FÉLIX, A.P. et al. Características físico-químicas de derivados proteicos de soja em dietas extrusadas para cães. Ciência Rural, v.40, n.12, p.2568-2573, 2010. Available from: <http://www. scielo.br/pdf/cr/v40n12/a790cr3938.pdf>. Accessed: 15 set. 2011.

LEÃO, V.P.C. et al. Cinza insolúvel em ácido em ensaio de digestibilidade em ovinos alimentados com cana-de-açúcar e feno da parte aérea da mandioca. Revista Brasileira de Saúde e Produção Animal, v.9, n.3, p.480-487, 2008. Available from: <http://revistas.ufba.br/index.php/rbspa/article/view/944/669>. Accessed: 29 set. 2011.

LEWIS, L.D. Stoll characteristics, gastrointestinal transit time and nutrient digestibility in dog fed different fiber sources. Journal of Nutrition, v.124, p.2716S-2718S, 1994. Available from: <http:// jn.nutrition.org/content/124/12_Supp1/2716S.long>. Accessed: 20 set. 2011.

LÔBO JR., M.F. et al. Coeficientes de digestibilidade aparente pelos métodos de indicadores e coleta total de fezes em cães. Arquivo Brasileiro de Medicina Veterinária e Zootecnia, v.53, n.6, p.691-694, 2001. Available from: <http://www.scielo.br/pdf/ abmvz/v53n6/a14v53n6.pdf>. Accessed: 20 set. 2011.

NACIONAL RESEARCH COUNCIL (NRC). Nutrient requirements of dogs and cats. Washington: National Academy, 2006. 426 p.

SALES, J.; JANSSENS, G. The use of markers to determine energy metabolizability and nutrient digestibility in avian species. World's Poultry Science, v.59, p.314-327, 2003. Available from: <http://hdl.handle.net/1854/LU-215944>. Accessed: 30 set. 2011.

SAS (Statistical Analysis System). User’s guide. Cary, NC, 1996. 584p.

STEIN, R.B.S. et al. Estimativa da digestibilidade aparente da matéria seca por meio de indicadores internos em equinos. Revista Brasileira de Zootecnia, v.35, p.504-511, 2006. Available from: <http://www.scielo.br/pdf/rbz/v35n2/a24v35n2.pdf>. Accessed: 30 set. 2011

VAN KEULEN, J.; YOUNG, B.A. Evaluation of acidinsoluble ash as a natural marker in ruminant digestibility studies. Journal of Animal Science, v.44, p.282-287, 1977. Available from: <http:// journalofanimalscience.org/content/44/2/282.full.pdf+html >. Accessed: 27 set. 2011.

ZUO, Y. et al. Digestion responses to low oligosaccharide soybean meal by ileally-cannulated dogs. Journal of Animal Science, v.74, p.2441-2449, 1996. Available from: <http://www. journalofanimalscience.org/content/74/10/2441.long>. Accessed: 29 set. 2011. 